\title{
Quantification of Atropine and Scopolamine in Different Plant Organs of Datura Metel: Development and Validation of High- Performance Liquid Chromatography Method
}

\author{
Hiba Al-Sayegh, Mohammad Zein, Ali Jaber*, Ghassan Ibrahim, Edmond Cheble \\ Laboratoire de Recherche et Développement des Médicaments et des Produits Naturels RDMPN, Faculty of Pharmacy, Lebanese University, Beirut,
} Lebanon.

*Corresponding Author: Ali JABER, Faculty of Pharmacy, Lebanese University, Beirut, Lebanon.

\section{Received Date: 09 Augusł 2021 | Accepted Date: 02 September 2021 | Published Date: 10 September 2021}

Citation: Hiba A Sayegh, M Zein, A Jaber, G Ibrahim, E Cheble. (2021) Quantification of Atropine and Scopolamine in Different Plant Organs of Datura Metel: Development and Validation of High-Performance Liquid Chromatography Method. Journal of Clinical and Laboratory Research; 3(3); DOI:10.31579/2768-0487/043

Copyright: () 2021 Ali JABER. This is an open-access article distributed under the terms of the Creative Commons Attribution License, which permits unrestricted use, distribution, and reproduction in any medium, provided the original author and source are credited.

Abstract
Datura metel (Solanaceae) from south Lebanon. The different parts of this plant contain the tropane
alkaloids atropine (AT) and scopolamine (SC), which are naturally muscarinic receptor antagonists. A
method has been developed for the extraction and HPLC-UV analysis of the AT and SC in different
parts of D. metel, namely seeds, capsule, leaf, and stem. This analytical method was validated and gave
a good detection response with linearity over a dynamic range of $0.03-0.17 \mathrm{mg} \mathrm{mL}^{-1}$ and recovery in
the range of $93.9-108.76 \%$. Limit of detection (LOD) and limit of quantification (LOQ) values were
32 and $98 \mu \mathrm{g} . \mathrm{mL}^{-1}$ for atropine and 31 and $93 \mu \mathrm{g} \cdot \mathrm{mL}^{-1}$ for scopolamine, allowing a reliable quantitation
of the target alkaloids. The solvent system Methanol/acetonitrile was the better choice for extracting
tropane alkaloids from different Datura parts. Capsule parts of the plant accumulate the highest amount
of scopolamine, while seeds accumulate the higher amount of atropine. Briefly, the order of
scopolamine concentrations in Datura metel parts, from Lebanon, was in capsules $>$ seeds $>$ leaves $>$
stems and for atropine, the concentrations were in seeds $>$ capsules $>$ stems $>$ leaves.
Keywords: tropane alkaloids; high-performance liquid chromatography (hplc); datura metel;
atropine; scopolamine

\section{Introduction}

Datura metel (D. metel) is a wild-growing plant of the Solanaceae family [1]. The name Datura is assumed to originate from Sanskrit Dustura or Dahatura [2], but is mostly known as Angel's and Devil's trumpet, Locoweed, Jimson weed, or Datura [3]. In Lebanon however, where it is widely distributed in several regions [4]; it is known as "Jawz-meaael". It comprises different types of phytochemicals such as flavonoids and glycosides. Its leaves and seeds are rich in alkaloids, such as atropine, scopolamine, and hyoscyamine [2]. Due to its alkaloid content, this plant was primarily used as an intoxicant and hallucinogen $[3,5]$.

Alkaloids, another class of nitrogen-containing secondary metabolites, are known to have wide pharmacological activity and have great potential for the development of new drugs to treat a wide array of diseases. Recently, in silico studies showed an affinity of tested alkaloids for binding to the receptor-binding domain of the SARS-CoV-2 spike protein, putatively preventing it from binding to the host cell [6]. Results show that the alkaloids are interesting compounds with potential use as bioactive agents against SARS-CoV-2 [7].

Furthermore, tropane alkaloids represent a group of over 200 compounds occurring primarily as metabolites produced by members of the Solanaceae family. They have in common a two-ringed structure characterized by a pyrrolidine and a piperidine ring sharing a single nitrogen atom and two carbons atoms [8]. Many alkaloids have been isolated from D. metel including hyoscine, hyoscyamine, meteloidine, scopolamine, ticlopidine, tropine, withametelline, and datumetine [9].

Atropine and scopolamine (also known as hyoscine) are the predominant tropane alkaloids naturally occurring in many members of the Solanaceae family, including Datura genera, which are widely spread throughout the world [10]. Scopolamine is an antimuscarinic agent and a smooth muscle relaxant. It is used in the treatment of motion sickness and preoperative 
medication $[11,12]$. It must be taken before the onset of motion sickness to be effective. Scopolamine is used to prevent nausea and vomiting caused by motion sickness or from anesthesia given during surgery.

Many healthy people have died from ingesting Datura, usually as a result of respiratory paralysis or heart failure [13]. For this reason, the assessment of tropane alkaloids concentration in plants of the Solanaceae family is highly important for toxicological and forensic purposes [14].

In our previous works, different part extracts of D. metel were tested for phytochemical screening, total phenols, flavonoids, alkaloids contents, and antioxidant activities $[15,16]$. The study revealed that the methanolic extracts exhibit a richness in secondary metabolites. The free radical scavenging methods DPPH and reducing power assay results prove a marked antioxidant activity of the extract [15]. On the other hand, there are few reports about the volatile components of D. metel EO's. Consequently, the present study was carried out to develop a validated method to quantify the atropine and scopolamine in extracts from different plant parts (leaves, stem, capsules, and seeds).

\section{Materials and Methods}

\section{Chemicals and Reagents}

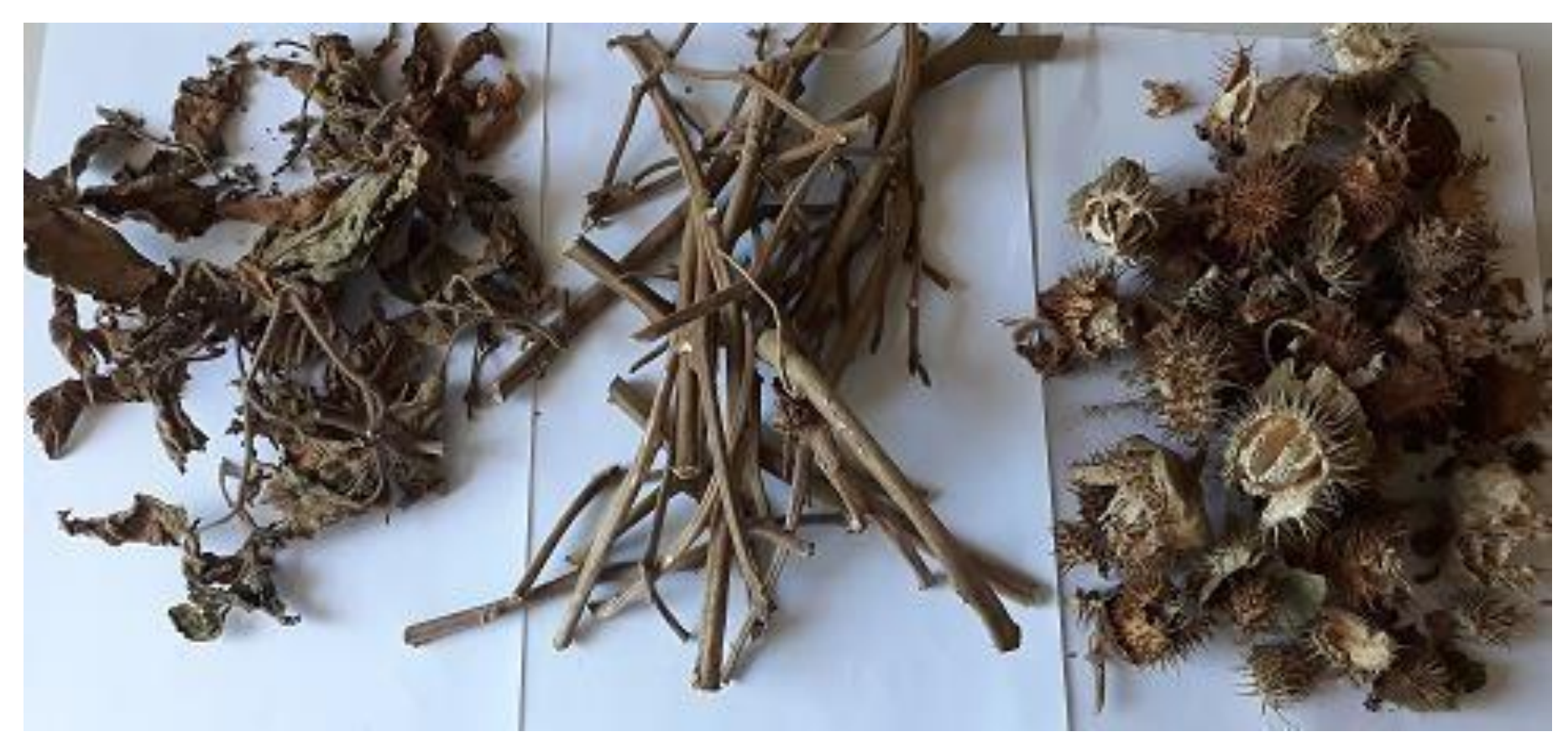

Figure 1: Datura's leaves, stems, and capsules

$15 \mathrm{~g}$ of Datura's grinded seeds/leaves/stems/capsules, were separately macerated for $24 \mathrm{hr}$ in either $\mathrm{MeOH} / \mathrm{ACN}$ (80/20) or EtOH/ACN (80/20). The experimental steps were performed in triplicates. The extraction
All of the chemicals used were of analytical grade. Methanol $(\mathrm{MeOH})$, ethanol $(\mathrm{EtOH})$, and acetonitrile $(\mathrm{ACN})$ were purchased from $\mathrm{BDH}$ (England). Atropine and scopolamine hydrobromide used as standards was bought from Alfa Aesar and Fluka Chemika respectively. The water used in all procedures was an ultrapure one, obtained from a water purification system (TKA MICROMED, Germany). Samples were weighed using a RADWAG XA 82/220/2X laboratory balance. The dried leaves and the dry bark were grinded using a POLYMIX grind mill. The absorbance values of the solutions were measured using a VWR UV6300PC double beam.

\section{Plant Material and Extracts Preparation}

The D. metel plant was collected in February of 2020, from the south of Lebanon in Blida $\left(33^{\circ} 08^{\prime} 0^{\prime \prime} \mathrm{N} 35^{\circ} 31^{\prime} 0^{\prime \prime} \mathrm{E}\right)$ region; was first, placed to dry, for several weeks in the laboratory. The samples were kept at room temperature until processing. The harvested plant materials initially underwent natural drying (in the shade, at room temperature) for four weeks, followed by segregating them into different parts namely leaves, capsules, stems, and seeds (Figure 1). Then they were grinded to fine powder, using a manual grinder. Finally, the grinded materials were stored in a well-sealed container for the extraction step.

protocol was illustrated in Figure 2. Finally, the weighted Datura extracts (DEs) were placed in Eppendorf in the fridge for analyses later on. 




Figure 2: A schematic representation of the extraction protocol used for the preparation of DE samples.

\section{Thin Layer chromatography}

Thin-layer chromatography (TLC) was used for the preliminary screening of alkaloids in DEs. To analyze DEs samples, samples were spotted as a single spot with a capillary tube onto the TLC plate. $20 \times 20 \mathrm{~cm}$ TLC plates coated with silica gel 60G F254 (Merk) were used. The eluent is a mixture of ammonia, $\mathrm{MeOH}$, and chloroform (0.1:8:1.9, v/v/v). A methanolic solution of scopolamine hydrobromide $\left(5 \mathrm{mg} \cdot \mathrm{mL}^{-1}\right)$ and another one of atropine sulfate $\left(5 \mathrm{mg} \cdot \mathrm{mL}^{-1}\right)$ were used as standards. After development, the plate was dried by a hairdryer. It was then sprayed with diluted Dragendorff's reagent to visualize the alkaloids. A red-orange spot indicated the presence of the alkaloid in the extract.

\section{HPLC-DAD system}

All measurements were accomplished using an HP 1100 Series LC system (Hewlett Packard, Palo Alto, CA, USA) equipped with a quaternary pump, a vacuum degasser, a column compartment, an auto sample, and a diode-array detector, and controlled by the HP Chemstation chromatography software. The analytical column was LiChrospher 60 RP-select B $5 \mu \mathrm{m}(250 * 4 \mathrm{~mm})$. Other equipments such as $\mathrm{pH}$ meter CG 820 (SCHOTT GERATE, made in West Germany), Ultrasonic cleaner (BRANSON 200, made in Taiwan), and vortex made by Daihan Scientific Co. (Korea) are also used in this study. 


\section{HPLC-DAD method: development and validation}

For the separations, the mobile phase used, in isocratic mode, was a mixture of $\mathrm{MeOH} / \mathrm{ACN} / \mathrm{ammonium}$ acetate 25:60:15 (pH adjusted with acetic acid to 4.6 ) respectively. The detection was carried at $210 \mathrm{~nm}$ by pumping the mobile phases at a flow rate of $1 \mathrm{~mL} \cdot \mathrm{min}^{-1}$ while the temperature of the column was maintained at $25 \mathrm{C}^{\circ}$. The injection volume was $20 \mu \mathrm{L}$ for $\mathrm{DE}$ and standard mixtures. Before injection, all the standards, sample solution as well as mobile phase were filtered through membrane filter $0.45 \mu \mathrm{m}$, then sonicated. All the samples were analyzed using the same conditions according to the analytical method optimized. After running, the peak areas corresponding to AT and SC were used to validate the method and quantify the target compounds in the plant parts.

The characteristics and the procedures used for validation were performed following the recommendations from the International Conference of
Harmonization (ICH) guidelines [17]. The performance criteria; linearity, selectivity, intra-assay and inter-assay precision, accuracy, the limit of detection (LOD), and limit of quantitation (LOQ) were determined.

\section{Results and Discussion}

Thin layer Chromatography is used to separate the constituents of secondary metabolites of plant extracts [18]. To ensure the presence of those major alkaloids, TLC was performed on the different extracts and the retention factors $\left(R_{f}\right)$ were calculated and compared against standards for identification. The outcomes of the TLC experiment of D. metel extract after visualization is shown in Figure 3 which reveals the presence of two orange spots in the extract solution, one at the same $R_{f}(0.75)$ as standard scopolamine and the other at the same $R_{\mathrm{f}}(0.5)$ as standard atropine, assuring their identities.

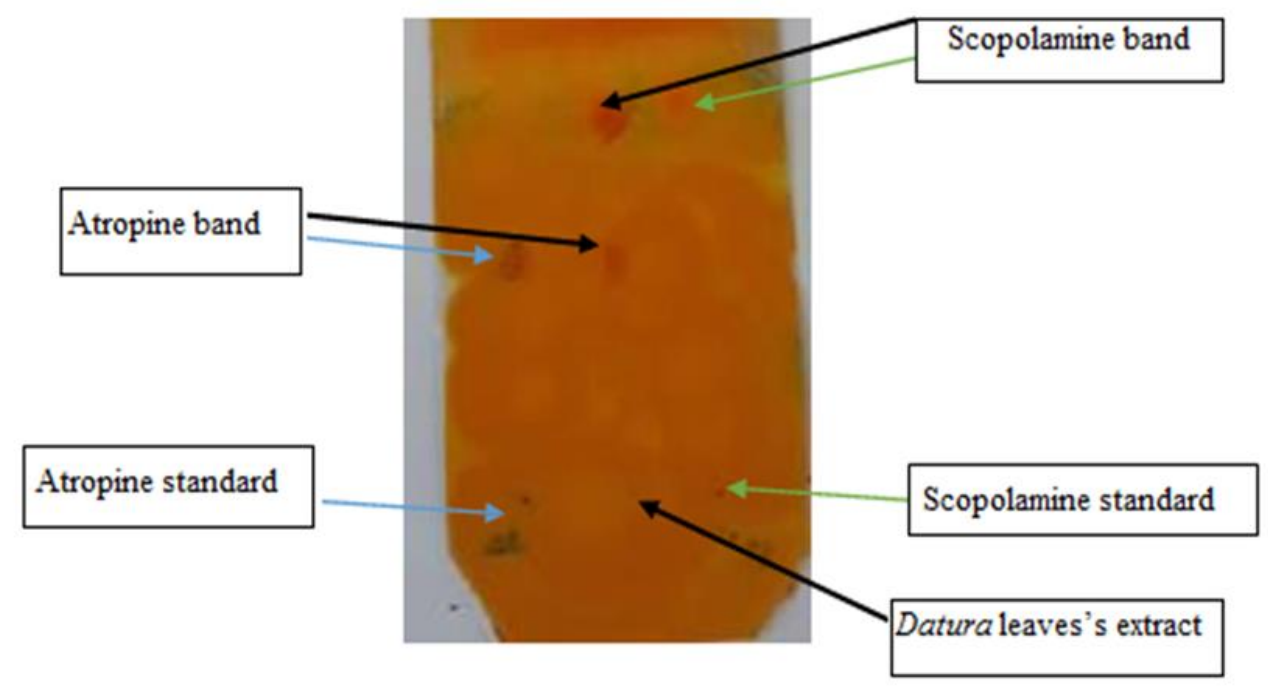

Figure 3: TLC plate of total leaves extract visualized by Dragendorff reagent.

The high-performance TLC was employed by Sharma et al. [19] to determine alkaloid "fingerprints" for morphotypes of D. metel and quantify atropine and scopolamine. Although TLC can be performed exceptionally rapidly, it regularly has destitute affectability: stain colors can blur, intemperate foundation recoloring frequently happens, and numerous components are not UV-active (or stain-reactive), making correct quantitative estimations exceptionally troublesome [20]. Several analytical methods have been employed for the analysis of tropane alkaloids including enzyme-linked immunosorbent assay (ELISA), paper chromatography, gas chromatography (GC), gas chromatography-mass spectrometry (GCMS), capillary electrophoresis (CE), and high-performance liquid chromatography (HPLC) [14].

Among the techniques used, HPLC is the most widely developed method for the quantification of tropane alkaloids. Thus we aimed to develop an HPLC-DAD method to quantify tropane alkaloids in the Lebanese D. metel. To ensure the similarity or the unique quality of plant materials from different locations, it is necessary to apply validated analytical methods and ensure that the developed methods meet their design goals. Evaluation of the developed method for selectivity for AT and SC was carried out by injecting $10 \mu \mathrm{L}$ of blank, standard, and sample solutions separately. The resulting chromatograms revealed no interfering signal appears at the retention times of interest (Figure 4, A). The peaks were identified by comparing the retention times of the analyzed compounds with authentic standards. SC (Figure 4, B) comes out with a retention time of around $3.3 \mathrm{~min}$, while AT (Figure 4, C) will be eluted around $4.8 \mathrm{~min}$. The resolution observed, between the AT and SC peaks, was greater than 1.5, which is acceptable when UV detection is applied [21].

The linearity and range of the method were tested using six different standard working solutions for each compound. Working solutions, of $0.03,0.05,0.07,0.11,0.13$, and $0.17 \mathrm{mg} . \mathrm{mL}^{-1}$, were prepared by diluting a standard stock methanolic solution $10 \mathrm{mg} \cdot \mathrm{mL}^{-1}$ with methanol. Each concentration was analyzed in triplicate under the same conditions. Finally, linear regression analysis was used to evaluate the linearity of the calibration curve by using the least square linear regression method.

The results of the linearity study (Figure 5 \& Figure 6) gave a linear relationship over the studied range. From the regression analysis, a linear equation was obtained: $y=15133 x-2.1728$ and $y=27092 x+263.52$ for $\mathrm{SC}$ and AT respectively. The correlation coefficient $\left(\mathrm{r}^{2}\right)$ was found to exceed 0.99 for in the two cases, indicating a linear relationship between the concentration of the analyte and the area under the peak. 


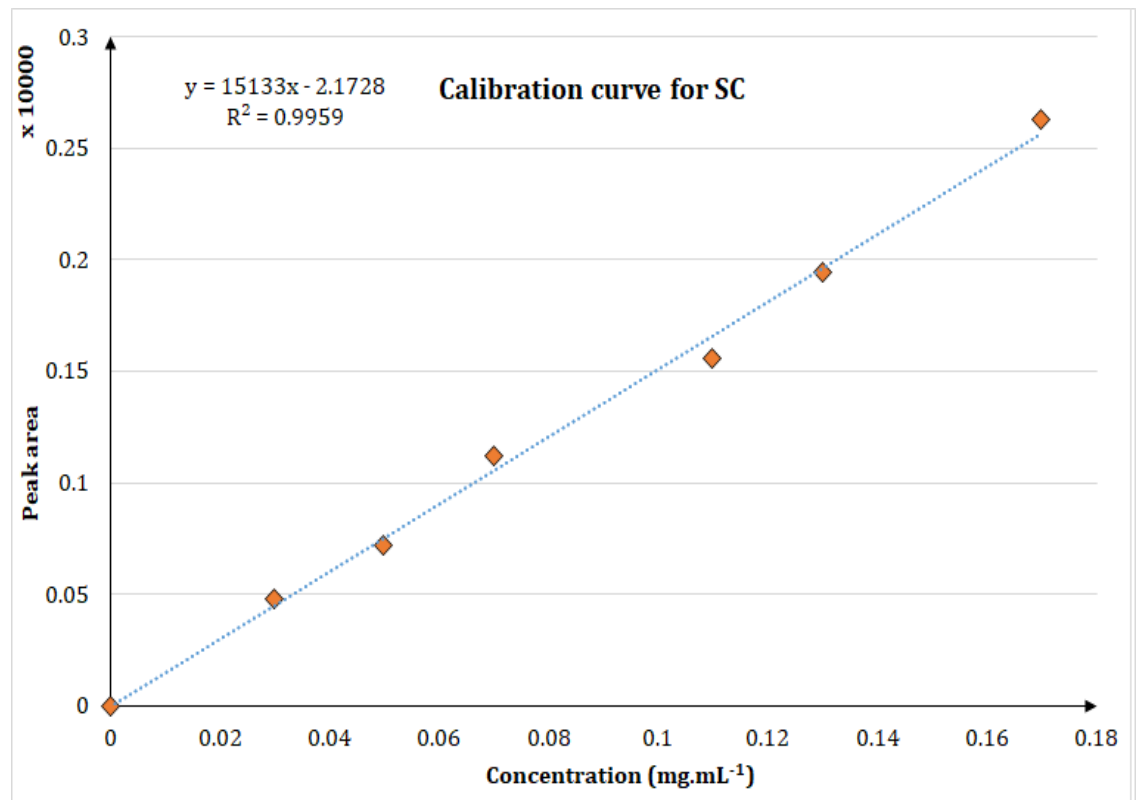

Figure 5: Calibration curve of SC.

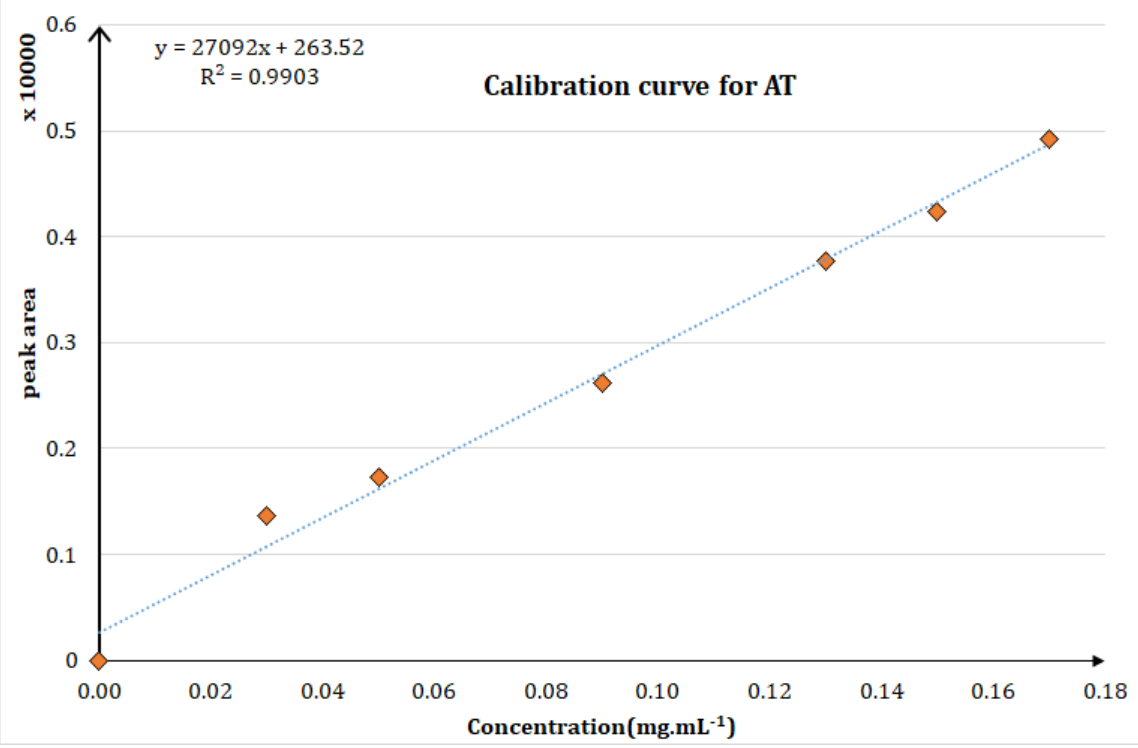

Figure 6: Calibration curve of AT.

The precisions were determined by the evaluation of the repeatability of the proposed methods. It was established by repeated measurements of standard solutions, 14 replicates (intraday) over three days (interday). The data obtained expressed in \% RSD, are listed in Table 1.

\begin{tabular}{|c|c|c|c|}
\hline & \multicolumn{2}{|c|}{$\% \mathrm{RSD}$} \\
\hline & & $\begin{array}{l}\text { Atropine } \\
\left(20 \mu \mathrm{g} \cdot \mathrm{mL}^{-1}\right)\end{array}$ & $\begin{array}{l}\text { Scopolamine } \\
\left(10 \mu \mathrm{g}_{\mathrm{mL}}^{-1}\right)\end{array}$ \\
\hline \multirow{3}{*}{ 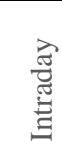 } & Day 1 & $0.94^{\mathrm{a}}$ & $0.86^{\mathrm{a}}$ \\
\hline & Day 2 & $0.6^{\mathrm{a}}$ & $1.4^{\mathrm{a}}$ \\
\hline & Day 3 & $0.47^{\mathrm{a}}$ & $0.6^{\mathrm{a}}$ \\
\hline \multicolumn{2}{|c|}{ Interday } & $0.27^{\mathrm{b}}$ & $0.28^{\mathrm{b}}$ \\
\hline \multicolumn{4}{|c|}{$\begin{array}{l}\text { a Data are mean values from fourteen determinations } \\
{ }^{\mathrm{b}} \text { Data are mean values from } 42 \text { determinations }\end{array}$} \\
\hline
\end{tabular}

Table 1: Intra-and interday precision of the peak area of SC and AT in standard solutions

The results of repeatability showed that the method was repeatable within the acceptable limits. The RSD for both scopolamine and atropine solutions were within limits. Low variation was observed in the peak areas intraday variation, ranged from 0.47 to 1.4 . The $\%$ RSD decrease to about 
0.28 for both standards in interday variations. The low values of standard deviation (better than $\pm 2 \%$ ) showed the precision and the repeatability of the retention time to be very good [22].

The limits of detection (LOD) and limits of quantification (LOQ) were calculated from the data obtained in the linearity study through the following equations (eq. 1) [17].

$\mathrm{LOD}=3.3 \frac{\sigma}{\mathrm{m}} \quad$ (eq. 1$)$
$\mathrm{LOQ}=10 \frac{\sigma}{\mathrm{m}} \quad$ (eq. 2$)$

were, $(\sigma)$ is the standard deviation of y-intercepts of regression analysis and $\mathrm{m}$ the calibration curve slope $(\mathrm{m})$.

The results showed that LOD and LOQ (Table 2) for scopolamine were 31 and $93 \mu \mathrm{g} \cdot \mathrm{mL}^{-1}$ respectively and that for atropine were 32 and 98 $\mu \mathrm{g} \cdot \mathrm{mL}^{-1}$ respectively. Although our numbers are still higher than obtained via LC-MS [21], the method can be used and applied. Further optimization is needed to increase the sensitivity of the method.

\begin{tabular}{|l|l|l|}
\hline Compounds & LOD in $\mu \mathrm{g} \cdot \mathrm{mL}^{-1}$ & LOQ in $\mu \mathrm{g} \cdot \mathrm{mL}^{-1}$ \\
\hline Scopolamine & 31 & 93 \\
\hline Atropine & 32 & 98 \\
\hline
\end{tabular}

Table 2: $L O D$ and $L O Q$ results for AT and SC standards

The accuracy of the assay method was determined by recovery studies at six concentration levels over three days.

The percent recovery of the method was determined from the founded and added concentrations. The percent recovery was found to range between $93-106 \%$ for SC, and between $95-110 \%$ for scopolamine. The average $\%$ RSD was 1.1 for SC and 1.5 for AT. \% Recovery and \% RSD were within the accepted limits from $80 \%$ to $120 \%$ [23], and not more than $5 \%$ [13], respectively, which indicates the applicability of the method for scopolamine and atropine analysis.

\section{Concentrations of Scopolamine and Atropine in Different DEs:}

The developed method was applied to determine the concentration of AT and SC in the different DEs. DEs were diluted and the concentration of scopolamine and atropine in these extracts were calculated according to the calibration curve obtained before.

The routine analysis of scopolamine and atropine was achieved under the conditions of the method developed by HPLC. Figure 4 D shows typical
HPLC chromatograms for standard materials of scopolamine and atropine. Based on the obtained concentrations, the first observation was that using methanol is by far better than ethanol one which results the highest concentration of alkaloids. Secondly, the results showed that AT and SC concentrations vary according to the investigated tissue of D. metel. The maximum amount of scopolamine in methanol extract was in the flower and seeds. SC concentration in methanol extract was 6.43 mg. $\mathrm{g}^{-1} \mathrm{DW}$ in flowers and $6.29 \mathrm{mg} . \mathrm{g}^{-1} \mathrm{DW}$ in seeds. Lesser concentrations of SC were in leaves and stems. The maximum amount of AT in methanol extract was in roots with a concentration of $0.894 \mathrm{mg} \cdot \mathrm{g}^{-1} \mathrm{DW}$ then in flowers, while the lowest concentration was in stems and leaves (Figure 7). In terms of ratio, the investigated plant part showed extremely high scopolamine to atropine ratios, this ratio is normally characterizing another species the D. inoxia [21]. On the other hand, it's known that varieties of the same species can possess characteristic differences in their alkaloid content [21]. Furthermore, the absence of pubescent leaves that distinguish D. inoxia from most other weedy Datura species [24], supports our results. Issaravanich et al. [25] find the lower amount of scopolamine in the leaves of Datura metel from Thailand.

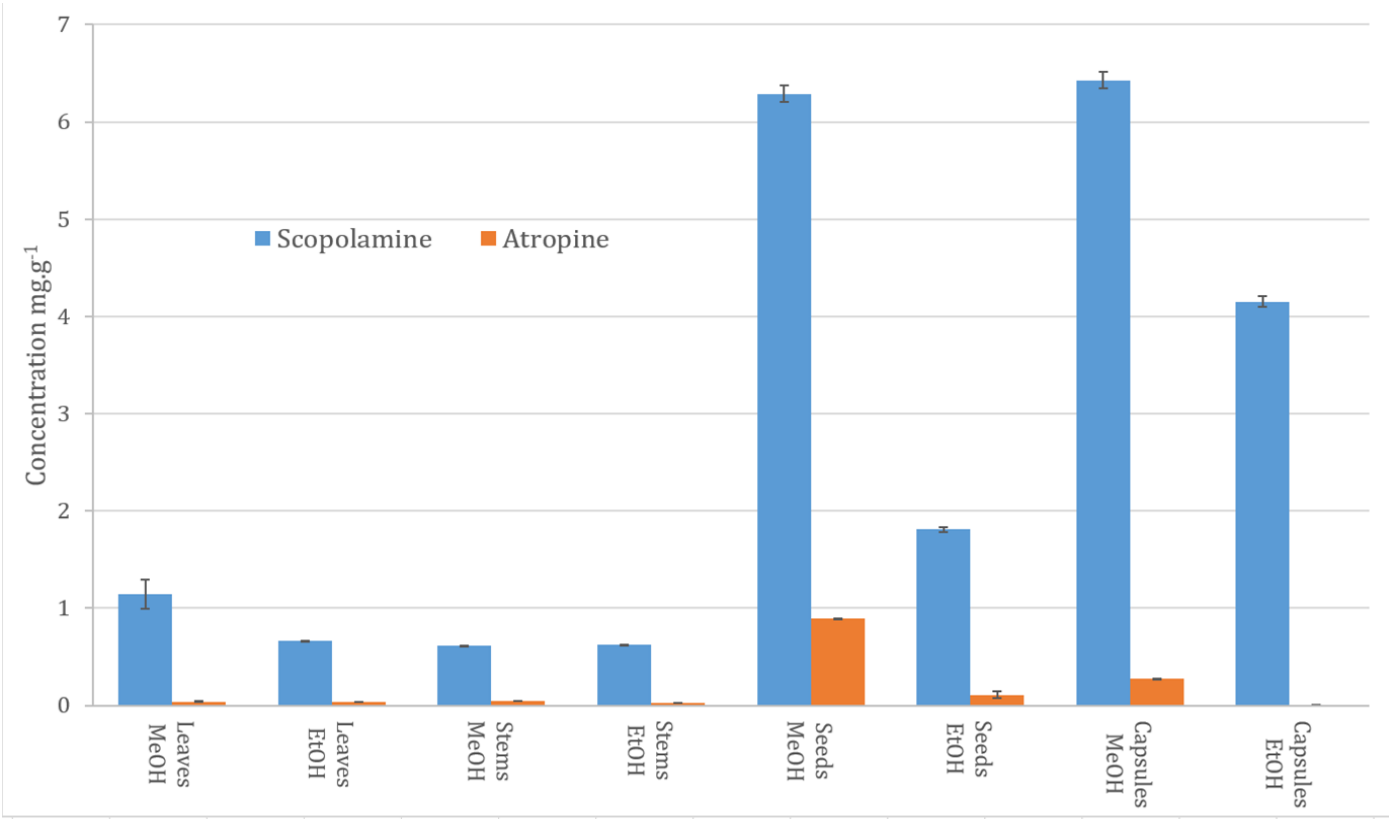

Figure 7: Comparison between the amounts of scopolamine in different studies. Data are mean of triplicates $\pm S D$. 


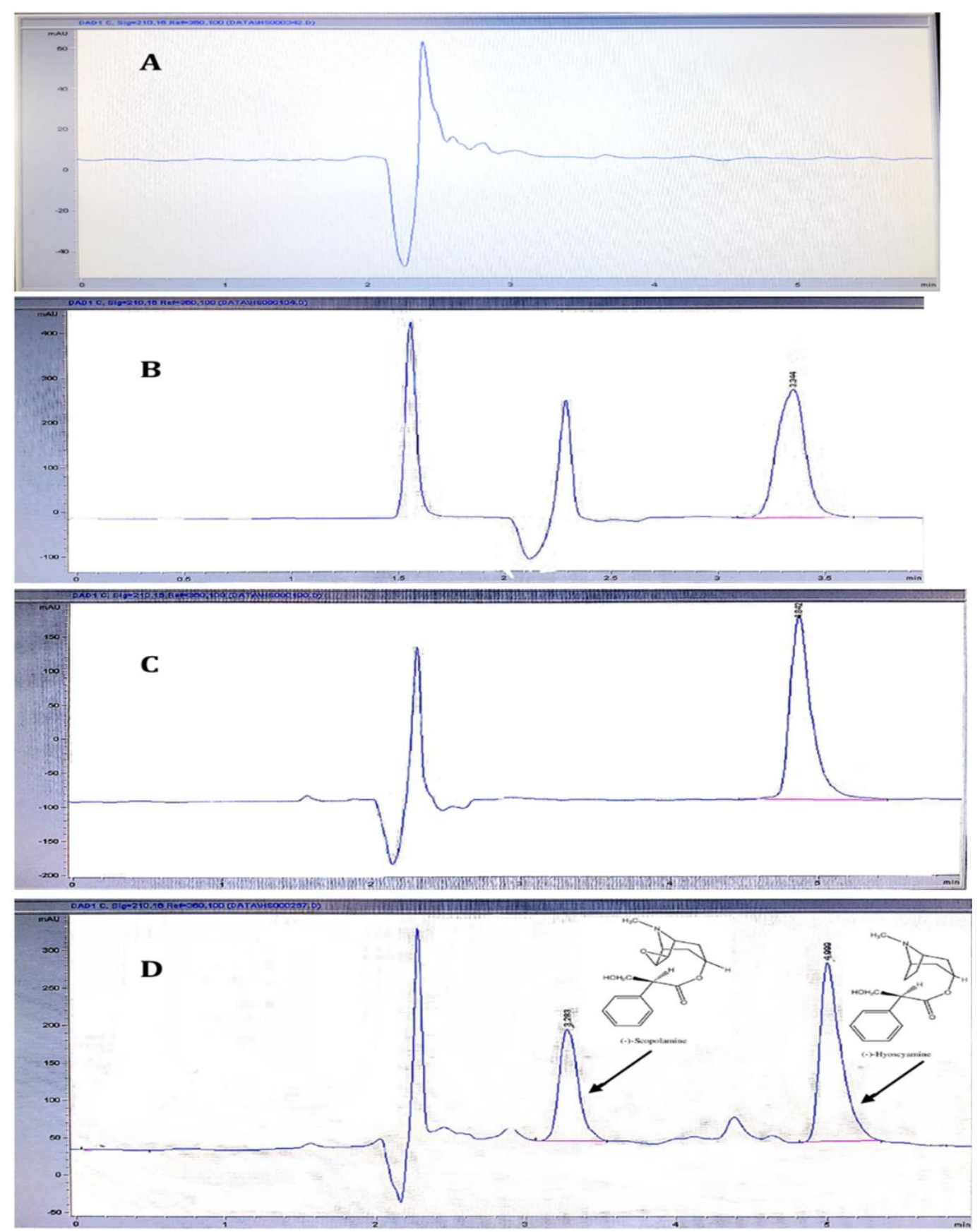

Figure 4: HPLC chromatograms of different solutions. A: chromatogram of blank solution; B: chromatogram of standard solution SC; C: chromatogram of standard solution AT; D: chromatogram of Datura metel leaf extract.

By comparing the concentrations of SC and AT measured in the D. metel from Lebanon with those reported for the same species in other countries (Table 3), we find big variations. AT and SC concentrations in leaves of D. metel growing wild in Russia ranged between $0.33 \mathrm{mg} . \mathrm{g}^{-1} \mathrm{DW}$ for SC and $0.90 \mathrm{mg} \cdot \mathrm{g}^{-1} \mathrm{DW}$ for AT which was the maximum amount between different parts of D. metel. Those concentrations were $0.02 \mathrm{mg} \cdot \mathrm{g}^{-1} \mathrm{DW}$ for SC and $0.01 \mathrm{mg} \cdot \mathrm{g}^{-1} \mathrm{DW}$ for AT in stems, a $0.63 \mathrm{mg} . \mathrm{g}^{-1} \mathrm{DW}$ of SC and
$0.11 \mathrm{mg} \cdot \mathrm{g}^{-1} \mathrm{DW}$ of AT in flowers. The maximum amount of SC has recorded in seeds with a concentration of $1.7 \mathrm{mg} \cdot \mathrm{g}^{-1} \mathrm{DW}$, while AT concentration was $0.23 \mathrm{mg} . \mathrm{g}^{-1} \mathrm{DW}$. Another study was carried out on Datura stramonium, concentrations of SC and AT were determined in three parts of the plant: leaves, stems, and roots. The maximum amount of SC was in the leaves with a concentration of $1.08 \mathrm{mg} \cdot \mathrm{g}^{-1} \mathrm{DW}$ and that of AT was in roots with a concentration of $1.39 \mathrm{mg} \cdot \mathrm{g}^{-1} \mathrm{DW}$.

\begin{tabular}{|l|l|l|l|l|l|l|}
\hline & Compounds & Leaves & Stems & Seeds & Capsules & Roots \\
\hline Our results & SC $\left(\mathrm{mg}^{-1} \mathrm{~g}^{-1}\right)$ & $1.14 \pm 0.15$ & $0.61 \pm 0.01$ & $6.29 \pm 0.08$ & $6.43 \pm 0.09$ & - \\
\hline
\end{tabular}




\begin{tabular}{|c|c|c|c|c|c|c|}
\hline & AT $\left(m g \cdot g^{-1}\right)$ & $0.040 \pm 0.001$ & $0.043 \pm 0.001$ & $0.89 \pm 0.01$ & $0.27 \pm 0.01$ & $\longrightarrow$ \\
\hline \multirow{2}{*}{ Russia [26] } & $\mathrm{SC}\left(\mathrm{mg} \cdot \mathrm{g}^{-1}\right)$ & $0.33 \pm 0.03$ & $0.02 \pm 0.02$ & $1.7 \pm 0.10$ & $0.63 \pm 0.05$ & $\longrightarrow$ \\
\hline & $\mathrm{AT}\left(\mathrm{mg} \cdot \mathrm{g}^{-1}\right)$ & $0.90 \pm 0.07$ & $0.01 \pm 0.001$ & $0.23 \pm 0.02$ & $0.11 \pm 0.01$ & \\
\hline \multirow{2}{*}{ Poland [27] } & $\mathrm{SC}\left(\mathrm{mg} \cdot \mathrm{g}^{-1}\right)$ & $1.08 \pm 0.09$ & $1.01 \pm 0.06$ & $\overline{ }$ & $\bar{z}$ & $0.19 \pm 0.01$ \\
\hline & AT $\left(\mathrm{mg} \cdot \mathrm{g}^{-1}\right)$ & $0.12 \pm 0.01$ & $1.28 \pm 0.05$ & $\bar{L}$ & $\bar{C}$ & $1.39 \pm 0.11$ \\
\hline
\end{tabular}

Table 3: Comparison of the amounts of AT and SC in between different locations.

Though the observation of the studies carried out on Datura gives importance to the study of the extent of these compounds despite the different content depending on plant part studied and place of growing. Environmental factors such as climatic conditions likely play an important role in the differences seen in plant contents of those alkaloids.

\section{Conclusion}

In the Datura plant, the main alkaloids were recorded to be scopolamine and atropine. In this research, we were able with both TLC and HPLC to identify qualitatively and quantitatively the presence of scopolamine and atropine compared to their standards. An HPLC method has been developed, and several validation parameters were evaluated to affirm that the method is compatible with the analysis of tropane alkaloids in Datura samples. The outcomes showed that the technique was suitable for quantification. The analytical method conditions and the mobile phase solvents provided good resolution for AT and SC. MeOH/ACN solvent system was the better choice for extracting tropane alkaloids from different Datura parts. The alkaloid content of D. metel varies to a great extent depending on the plant part concerned. The capsule was the tissue that accumulates the higher amount of SC, while seeds accumulate the higher amount of AT. SC concentrations in D. metel parts decrease as follows capsules $>$ seeds $>$ leaves $>$ stems and for atropine the highest concentrations were in seeds and the lowest in leaves.

\section{Acknowledgments}

The authors gratefully acknowledge the financial support from Lebanese University (Faculty of Pharmacy).

\section{References}

1. Tijani AA, Eyineyi UG, Ibrahim JA, Okhale SE. (2015). Neurotoxicological impacts of Datura metel Linn. (Family: Solanaceae) leaves extract in mice. J Neurobehav Sci 2: 97-101.

2. Deepa M, Sugitha N, Mythili S, Sathiavelu A. (2014). Antioxidant activity and phytochemical analysis of Datura metel. Int J Drug Dev \& Res 6:280-258.

3. Okwu DE, Igara EC. (2009). Isolation, characterization and antibacterial activity of alkaloid from Datura metel Linn leaves. Afr J Pharm Pharmacol 3:277-281

4. Tohmé G, Tohmé H. (2014). Illustrated flora of Lebanon. National Council for Scientific Research.

5. Morakinyo Sanni D (2016). Inhibitory effect of extracts from Datura metel leaf on mushroom tyrosinase. Am J Life Sci 4: 4750.

6. Fielding BC, da Silva Maia Bezerra Filho C, Ismail NSM, Sousa DP de (2020). Alkaloids: therapeutic potential against human coronaviruses. Molecules 25: 5496.

7. Suryawanshi SS, Patil RS, Jayannache PB, Palled MS, Alegaon SG, Zaranappa (2020). Screening and assessment of selected alkaloids as potential inhibitors of COVID-19 protease enzyme. J Glob Trends Pharm Sci 7711-7718.

8. (2008). Tropane alkaloids (from Datura sp.) as undesirable substances in animal feed - Scientific Opinion of the Panel on Contaminants in the Food Chain. EFSA J 6:691

9. Monira KM, Munan SM (2012). Review on datura metel: A potential medicinal plant. Glob J Res Med Plants Indig Med 1: 123-132.
10. Aniszewski T (2007). Alkaloids - Secrets of life: Alkaloid chemistry, biological significance, applications and ecological role. Elsevier.

11. Wyk B-EV, Wink M. (2004). Medicinal plants of the world: An illustrated scientific guide to important medicinal plants and their uses. Timber Press.

12. Steenkamp PA, Harding NM, van Heerden FR, van Wyk B-E. (2004). Fatal Datura poisoning: identification of atropine and scopolamine by high performance liquid chromatography/photodiode array/mass spectrometry. Forensic Sci Int 145: 31-39.

13. Koetz M, Santos TG, Rayane M, Henriques AT (2017). Quantification of atropine in leaves of atropa belladonna: development and validation of method by high-perfomance liquid chromatography (HPLC). Drug Anal Res 1: 44-49.

14. Boros B, Farkas Á, Jakabová S, Bacskay I, Kilár F, Felinger A (2010). LC-MS quantitative determination of atropine and scopolamine in the floral nectar of datura Species. Chromatographia 71: 43-49.

15. Jaber A, Edmond C, Ibrahim G, Lamis A-H (2019). Phytochemical study and antioxidant activity of extract from the leaves of lebanese datura metel 1. Eur J Pharm Med Res 6: 65-71.

16. Jaber A, Cheble E, Ibrahim G, Al-Harakeh L, Dorra Z (2021). Chemical composition of essential oil and total alkaloid of extract from leaves of Lebanese Datura metel L. Curr Trends Pharma Clinical Trials. 4(1): 180027.

17. Singh J (2015). International conference on harmonization of technical requirements for registration of pharmaceuticals for human use. J Pharmacol Pharmacother 6:185-187.

18. Bladt S. (1996). Plant drug analysis: A thin layer chromatography atlas, 2nd ed. Springer-Verlag, Berlin Heidelberg.

19. Sharma V, Sharma N, Singh B, Gupta R. (2009). Cytomorphological studies and HPTLC fingerprinting in different plant parts of three wild morphotypes of Datura metel L. "Thorn Apple" from North India. Int J Green Pharm 3:40-46.

20. Cinelli MA, Jones AD (2021). Alkaloids of the genus Datura: Review of a rich resource for natural product discovery. Mol Basel Switz 26: 2629.

21. Jakabová S, Vincze L, Farkas Á, Kilár F, Boros B, Felinger A (2012). Determination of tropane alkaloids atropine and scopolamine by liquid chromatography-mass spectrometry in plant organs of Datura species. J Chromatogr A 1232: 295-301.

22. United Nations Office on Drugs and Crime, Laboratory and Scientific Section (2009). Guidance for the validation of analytical methodology and calibration of equipment used for testing of illicit drugs in seized materials and biological specimens: a commitment to quality and continuous improvement. United Nations, New York.

23. Shikanga EA, Kamatou GPP, Chen W, Combrinck S, Viljoen AM (2012). Validated RP-UHPLC PDA and GC-MS methods for the analysis of psychoactive alkaloids in Sceletium tortuosum. South Afr J Bot 82: 99-107.

24. Parsons WT, Parsons WT, Cuthbertson EG (2001). Noxious weeds of Australia. Csiro Publishing.

25. Issaravanich S, Ruangrungsi N, Palanuvej C, Vipunngeun N, Rungsihirunrat K (2013). Microscopic, molecular and 
scopolamine content evaluations of datula metel L. var. metel and d. metel L. var. fastuosa in Thailand. 4:13.

26. Temerdashev AZ, Kolychev IA, Kiseleva NV (2012). Chromatographic determination of some tropane alkaloids in Datura metel. J Anal Chem 67: 960-966.
27. Śramska P, Maciejka A, Topolewska A, Stepnowski P, Haliński ŁP (2017). Isolation of atropine and scopolamine from plant material using liquid-liquid extraction and EXtrelut ${ }^{\circledR}$ columns. J Chromatogr B Analyt Technol Biomed Life Sci 1043: 202-208.
Ready to submit your research? Choose Auctores and benefit from:

$>$ fast, convenient online submission

$>$ rigorous peer review by experienced research in your field

$>$ rapid publication on acceptance

$>$ authors retain copyrights

$>$ unique DOI for all articles

$>$ immediate, unrestricted online access

At Auctores, research is always in progress.

Learn more auctoresonline.org/journals/journal-of-clinical-andlaboratory-research 